\title{
Auricular Lobuloplasty
}

\author{
Ahmet Altıntaş ${ }^{1}$, Mustafa Çelik ${ }^{2}$, Yakup Yeğin ${ }^{2}$, Gürkan Kayabaşoğlu ${ }^{3}$ \\ ${ }^{1}$ Department of Otorhinolaryngology, Fatih Medical Park Hospital, İstanbul, Turkey \\ Original Investigation $>{ }^{2}$ Department of Otorhinolaryngology, Bakırköy Dr. Sadi Konuk Training and Research Hospital, İstanbul, Turkey \\ ${ }^{3}$ Department of Otorhinolaryngology, Sakarya University Training and Research Hospital, Sakarya, Turkey
}

Abstract

Cite this article as: Altıntaş A, Çelik $M$, Yeğin Y, Kayabaşoğlu G. Auricular Lobuloplasty. Turk Arch Otorhinolaryngol 2017; 55: 172-6.

\section{Address for Correspondence:} Mustafa Çelik E-mail: dr.mcelik@yahoo.com Received Date: 15.07.2017 Accepted Date: 08.10.2017

(c) Copyright 2017 by Official Journal of the Turkish Society of Otorhinolaryngology and Head and Neck Surgery Available online at www.turkarchotolaryngol.net DOl: 10.5152/ta0.2017.2675
Objective: To evaluate surgical outcomes of auricular lobuloplasy.

Methods: In total, 13 patients (10 females and 3 males; average age, $32.3 \pm 8.48$ years; range 21 - 44 years) who underwent auricular lobuloplasty were included in this study. Demographic characteristics, cause of surgery, presence of complications, and patient satisfaction were evaluated.

Results: The mean follow-up was $16.5 \pm 9.6$ months with the shortest and the longest follow-up being 6 and 34 months, respectively. Surgeries were performed under local anesthesia in 10 cases $(76.9 \%)$ and under general anesthesia in three cases (23.1\%). Lo-

\section{Introduction}

Facial aesthetics develops depending on the symmetry and harmony of the facial skeletons and soft structures. The auricular lobule has an important place in face and ear aesthetics. It is generally conical and round in shape and is an important anatomical formation that allows women to wear accessories such as earrings $(1,2)$. It has different shapes, and sometimes it can attract a lot of attention on the face. It is known that Tutankhamun, an ancient Egyptian pharaoh, had a stretched auricular lobule (3). In Africa, the Ivan and Kayan tribes adorn their auricular lobules with heavy and large earrings, causing the lobules to become wide and sagging (4).

In different societies, auricular lobules are pierced for religious, cosmetic, and social reasons; however, they are associated with the level of societal development. Partial or complete tear of the auricular lobule is an important situation that is very common in women and leads to cosmetic deformity. The use of earrings and buloplasty were performed in eight cases (61.5\%) with a diagnosis of partial lobule cleft, four cases (30.7\%) with a diagnosis of elongated lobule, and one case (7.8\%) with a diagnosis of congenital earlobe cleft. There were no postoperative complications and revision surgery was not necessary for any of the patients.

Conclusion: Multiple surgical techniques exist for repairing earlobe deformities. Auricular lobuloplasty is a surgical procedure that has several advantages including safety, ease of use, and effectiveness.

Keywords: Elongated auricular lobule, earlobe cleft, auricular lobuloplasty heavy metals such as "piercing" leads to permanent deformities in the auricular lobule owing to the effect of gravity (5-10). It causes tearing in the auricular lobule due to age, trauma, and mechanical factors. The most frequent causes of the clefts in the auricular lobule are that the holes made in the auricule for ornamentation expand over time and that the ornaments separate the lips of the cleft from each other with the influence of gravity, thereby causing permanent holes (9).

According to the data of the American Society for Aesthetic Plastic Surgery in 2015, approximately 40,000 people per year undergo ear surgery for cosmetic purposes for ear defects developing because of trauma or wearing heavy earrings. Aesthetic ear interventions are the $6^{\text {th }}$ most common surgical procedures in males and 14th most common surgical procedures in females. Aesthetic ear surgery is most frequently performed at the age of 19-34 years, but there has been an increase in those below 18 years (11). 
In the present study, the results of 13 patients who underwent auricular lobuloplasty for elongated or cleft auricular lobule were evaluated.

\section{Methods}

Patients who underwent auricular lobuloplasty for elongated auricular lobule or cleft auricular lobule in the Otorhinolaryngology, Head and Neck Surgery Department of Fatih Medical Park hospital between January 2014 and May 2016 were included in this retrospective clinical trial. The study was conducted in accordance with the Guidelines for Good Clinical Practice and the Helsinki Declaration principles. Because the study is retrospective, informed consents have not been received from the patients. Approval of the local ethics committee (ethics committee no.: 2017/04/01) was received from Bakırköy Dr. Sadi Konuk Training and Research Hospital. A total of 13 patients, 10 women (76.9\%) and three men (23.1\%), were included in the study. Their ages ranged from 21 to 44 years, and the mean age was $32.3 \pm 8.48$ years. Surgical consent was obtained from all the patients preoperatively.

All operations were performed by the same surgeon under local or general anesthesia. Photographs of all the patients were taken preoperatively and in the postoperative first month (Figure 1ad). The satisfaction of all the patients was assessed by scoring between 1 and 10 using the visual analog scale (VAS) in the postoperative first month. Demographic characteristics of all the patients were obtained from the files in the hospital registry system. Demographic characteristics of all the patients, the cause of auricular lobuloplasty, the presence of complications, and patient satisfaction were evaluated.

\section{Surgical technique}

Technique 1: After the auricule and its surrounding surface were cleaned with the antiseptic solution of $10 \%$ povidone iodine (Poviiodeks Antiseptik ${ }^{\circledR}$; Kim-Pa Pharmaceutical Lab. Trade Co. Ltd., Istanbul, Turkey), injection of $1 \%$ lidocaine without epinephrine was administered in four quadrants, which were the anterior, posterior, superior and inferior of the auricular region, and a period of 10-minute was given for the effect. A surgical incision line was drawn with a marking pen (Figure 2a). Triangular tissue was removed with wedge resection from the inferior elongated lobule. Two pedicles were created as anterior and posterior (Figure $2 \mathrm{~b}$ ). A second triangular tissue with the base at the medial region and the apex at the lateral region was excised from the long posterior pedicle to match with the anterior pedicle in size. Therefore, a lobule with three pedicles was created (Figure 2c). These three-pedicles were combined primarily with $6 / 0$ polypropylene ${ }^{\circledR}$ suture to ensure contour continuity (Figure $2 \mathrm{~d}$ ). The patient was followed up for 10 days postoperatively using local antibiotic ointment and oral antibiotics. Sutures were taken on the $7^{\text {th }}$ postoperative day.

Technique 2: The same surgical procedure was applied in patients with cleft auricular lobule. After the edges of the cleft were de-epithelialized, they were converted into complete clefts and anterior and posterior pedicles were created. A lobule with
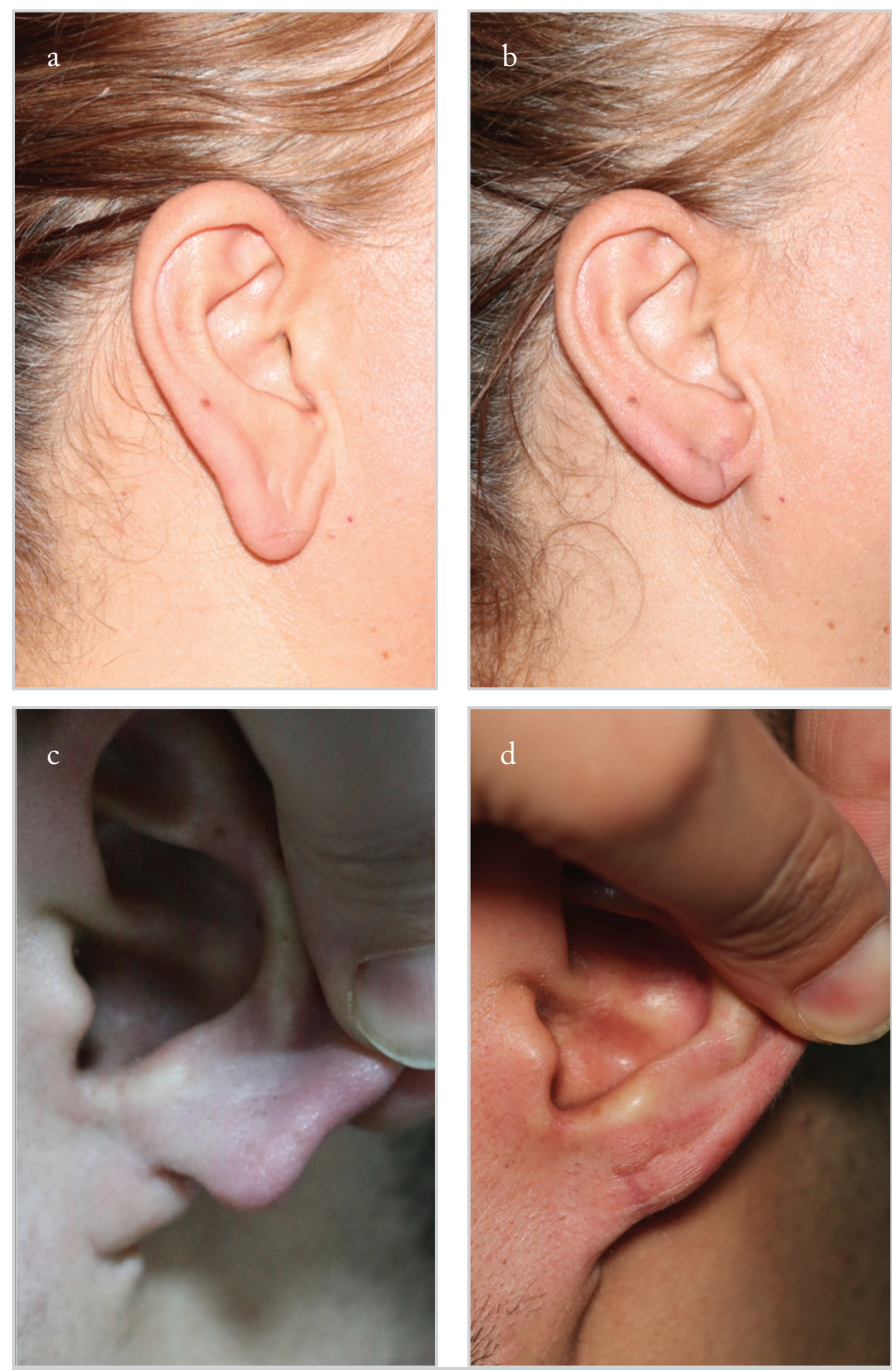

Figure 1. a-d. Preoperative (a,c) and postoperative first month (b, d) images of the patients who underwent auricular lobuloplasty
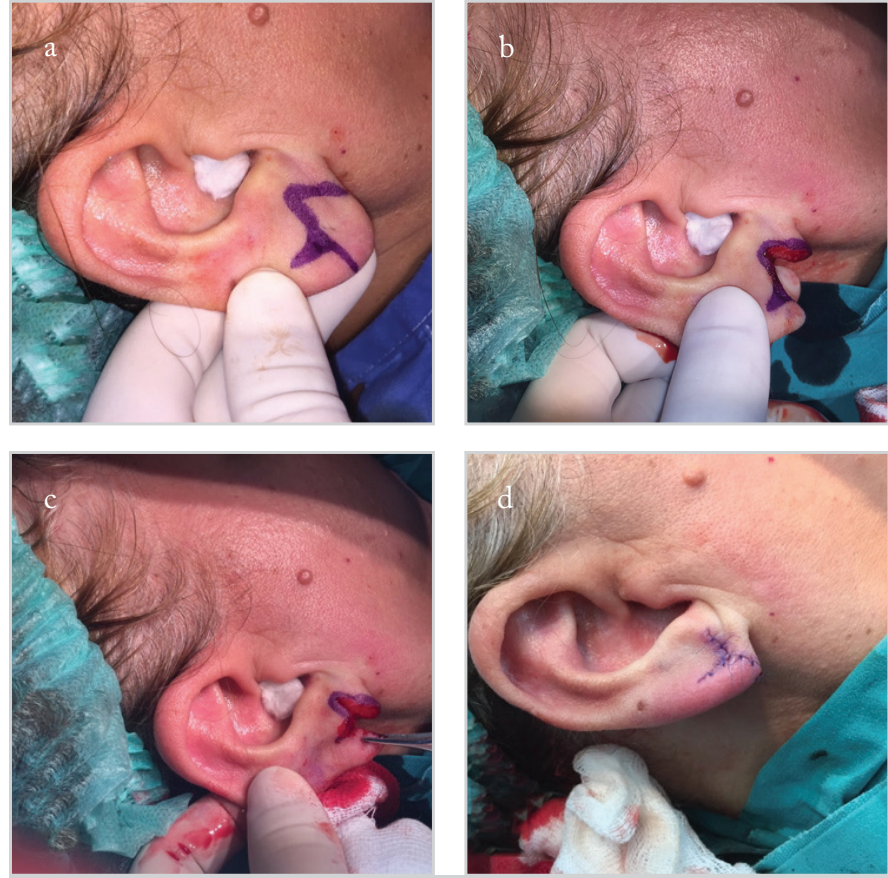

Figure 2.a-d. Surgical stages of a patient who underwent lobuloplasty for elongated auricular lobule 
Table 1. General characteristics of the patients and outcome evaluation

\begin{tabular}{|c|c|c|c|c|}
\hline Age and gender of the patient & Side & Type of anesthesia & Complication & Patient satisfaction* \\
\hline 21 years, female & Bilateral, partial lobule cleft & LA & None & Good (7) \\
\hline 22 years, female & Bilateral, partial lobule cleft & LA & None & Good (7) \\
\hline 24 years, female & Bilateral, partial lobule cleft & LA & None & Good (6) \\
\hline 25 years, female & Bilateral, partial lobule cleft & LA & None & Good (7) \\
\hline 26 years, male & Left side, congenital lobule cleft & GA (along with septorhinoplasty) & None & Very good (9) \\
\hline 28 years, female & Bilateral, elongated lobule & GA (along with otoplasty) & None & Very good (10) \\
\hline 32 years, female & Bilateral, partial lobule cleft & LA & None & Good (8) \\
\hline 35 years, female & Bilateral, partial lobule cleft & LA & None & Good (7) \\
\hline 37 years, female & Bilateral, partial lobule cleft & LA & None & Good (7) \\
\hline 41 years, female & Bilateral, elongated lobule & GA (along with otoplasty) & None & Good (8) \\
\hline 42 years, female & Bilateral, partial lobule cleft & LA & None & Good (7) \\
\hline 43 years, male & Bilateral, elongated lobule & LA & None & Good (7) \\
\hline 44 years, male & Bilateral, elongated lobule & LA & None & Good (8) \\
\hline
\end{tabular}

*According to the visual analog scale, 6-8: good; 9-10: very good

LA: local anesthesia; GA: general anesthesia

three pedicles was created by excising a triangle from the posterior pedicle with wedge resection. The suturing was performed in the same way. Monitoring of the patient was performed in the same way.

\section{Results}

The follow-up period of all the patients was 6-34 months, and the mean duration was $16.5 \pm 9.6$ months. The operations were performed under local anesthesia in 10 cases (76.9\%) and under general anesthesia in three cases (23.1\%). Lobuloplasty was applied in eight patients (61.5\%) for partial lobule cleft, in four patients (30.7\%) for elongated lobule, and in one patient (7.8\%) for coloboma lobuli (congenital lobule cleft). While otoplasty was applied along with lobuloplasty in two patients under general anesthesia, septorhinoplasty was applied along with lobuloplasty in one patient. Postoperative complications were not observed in any patient. The surgical outcome was consistent with the expectations of the patients. The characteristics and satisfaction scores of all the patients according to the VAS are summarized in Table 1 . No revision surgery was required in any of the patients.

\section{Discussion}

Auricular lobuloplasty can be performed for auricular lobule clefts, congenital deformities, aging, keloid formation, or auricular tumors $(12,13)$. Auricular lobule clefts are the most common cause of auricular lobuloplasty, and there are different classifications for auricular lobule clefts in the literature. Sharma et al. (14) divided the lobule clefts into two groups as congenital clefts and acquired clefts, and they divided acquired clefts into two groups as partial and complete clefts. Blanko-Davila and Vasconez (8) classified the partial lobule clefts according to the distance between the original hole and the lower limit of the lobule. Boo-Chai (15) divided the lobule defects into two groups as congenital and acquired and called the congenital clefts as "col- oboma lobuli”. Partial auricular clefts are usually seen bilaterally in women wearing heavy earrings for a long time. Complete lobule clefts occur in young adults as a result of wearing earrings unilaterally for a long time or as a result of trauma $(11,13)$. Hassen (9) reported unilateral lobule tear in $58 \%$ of the cases, bilateral lobule tear in $42 \%$, partial lobule tear in $29 \%$, and complete lobule tear in $71 \%$. Khilnani and Thaddanee (12) observed that $54.8 \%$ of the patients had partial clefts and $45.2 \%$ had complete clefts. In the present study, partial lobule cleft was found in eight cases (61.5\%) and congenital lobule cleft in one case (7.8\%).

The repair of auricular lobule defects with simple linear closure was first reported by McLaren (16) in 1954. Subsequently, different surgical techniques were described for the repair of auricular lobule defects in the literature. Tan (17) presented a "punch" technique for lobular defects smaller than $4 \mathrm{~mm}$. Relatively good results were reported with the "z-plasty" technique in 10 cases by Abenavoli (18). Miller and Eisbach (19) documented that they made repairs using the z-plasty technique after converting the partial defects into complete defects. One of the more innovative approaches to repair partial defects is the "parallel opposed flap" technique proposed by Reiter and Alford (20). In this technique, the anterior and posterior faces of the defect are brought close to each other and are sutured. While this technique is available for the repair of small defects, it is not appropriate for the repair of large defects.

Niamtu (4) suggested that the wound lips should be closed after the scar excision in small clefts that are in the upper twothirds part of the auricular lobule and that the closing procedure should be performed after the partial clefts are converted into complete clefts in the lower one-third.

While Hassen (9) did not excise the cleft edges in the lobule clefts, Zoltie (21) reported performing the excision leaving the 
apical part of the cleft intact, which would create a rectangular flap on the anterior and posterior edges of the cleft. Rich et al. (22) noted that they were able to repair the defect by excising tissue on the posterior surface of the lobule as much as they did on the anterior surface. In small defects, Vujevich et al. (6) defined the repair of the wound edges with single continuous suture as in purse string after the defect wall was de-epithelialized. In wide partial lobular defects, de la Sotta et al. (23) described the surgical technique in which the defects were closed after joining the wound orifices with wedge resection at three corners of the defect.

A lot of different techniques have been described in the literature and the technique that is appropriate for the patient should be selected. In the present study, as suggested by Miller and Eisbach (19), partial clefts were converted into complete clefts after the edges of the clefts were de-epithelialized first. Anterior and posterior pedicles were formed. A lobe with three pedicles was created by excising a triangle with wedge resection from the posterior pedicle. In addition, a three-pedicle flap was created in the elongated lobule to make the lobule smaller.

There is no consensus in the literature as to when the lobule can be punctured again after the reconstruction of the auricular clefts. Watson (24) and Vujevich et al. (6) reported that they waited for at least 6 weeks after the repair of the lobular cleft defect to re-puncture the lobule. In the present study, it was recommended that all the patients should also wait for at least six weeks to re-puncture the auricular lobule.

The satisfaction rate related to the cosmetic results of lobuloplasty has been reported as $92 \%-100 \%$ (18-22). The high level of satisfaction can be attributed to the small size of the surgical field, the simple and easy implementation of the techniques, and the low rate of complications. All of our patients were satisfied with the results of the lobuloplasty operation.

Complication rates after lobuloplasty were reported between $0 \%$ and $33.3 \%$ (8-21). Complications include hypertrophic scar, depressed scar, wide scars, recurrence of the cleft, and wound infection. In the present study, no complication was observed in any of the patients during the postoperative follow-up period.

\section{Conclusion}

Auricular lobuloplasty is an easy surgical procedure. This surgery has a low risk of complication with very satisfactory results; therefore, it should be recommended for patients with lobular deformities.

Ethics Committee Approval: Ethics committee approval was received for this study from the ethics committee of Bakırköy Dr. Sadi Konuk Training and Research Hospital (2017/04/01).

Informed Consent: Informed consent was not obtained due to the retrospective nature of the study.

Peer-review: Externally peer-reviewed.
Author Contributions: Concept - A.A., Y.Y., M.Ç., G.K.; Design A.A., Y.Y., M.Ç., G.K.; Supervision - A.A., Y.Y., M.Ç., G.K.; Resource - A.A., Y.Y., M.Ç., G.K.; Materials - A.A., Y.Y., M.Ç., G.K.; Data Collection and/or Processing - A.A., Y.Y., M.Ç., G.K.; Analysis and/or Interpretation - A.A., Y.Y., M.Ç., G.K.; Literature Search A.A., Y.Y., M.Ç., G.K.; Writing - A.A., Y.Y., M.Ç., G.K.; Critical Reviews - A.A., Y.Y., M.Ç., G.K.

Conflict of Interest: No conflict of interest was declared by the authors.

Financial Disclosure: The authors declared that this study has received no financial support.

\section{References}

1. Patrocı́nio LG, Morais RM, Pereira JE, Patrocínio JA. Earlobe cleft reconstructive surgery. Braz J Otorhinolaryngol 2006; 72: 447-51. [CrossRef]

2. Sinha M. Techniques for correction of acquired or congenital earlobe repair. J Plast Reconstr Aesthet Surg 2006; 59: 1009-10. [CrossRef]

3. Hawass Z. The golden age of Tutankhamun: divine might and splendour in the New Kingdom. American University in Cairo Press 2004; 61. ISBN 977-424-836-8.

4. Niamtu J. Eleven pearls for cosmetic earlobe repair. Dermatol Surg 2002; 28: 180-5. [CrossRef]

5. Suh H. Traumatic cleft earlobe repair using double triangular flap from epithelialized skin of cleft margin. J Craniofac Surg 2014; 25: 976-7. [CrossRef]

6. Vujevich J, Goldberg LH, Obagi S. Repair of partial and complete earlobe clefts: a review of 21 methods. J Drugs Dermatol 2007; 6: 695-9.

7. Rich JD, Gottlieb V, Shesol BF. A simple method for correction of the pixie earlobe. Plast Reconstr Surg 1982; 69: 136-8. [CrossRef]

8. Blanco-Davila F, Vasconez HC. The cleft earlobe: a review of methods of treatment. Ann Plast Surg 1994; 33: 677-80. [CrossRef]

9. Hassen AS. Surgical correction of cleft earlobes Hassen. Al Azhar Assiut Med J 2016; 14: 85-8. [CrossRef]

10. Shen W, Cui J, Chen J, Chen H, Zou J,Ji Y. Inversion of the flap at the lower ear and restoration of the flap at postauricular skin for reconstruction of the earlobe. J Craniofac Surg 2012; 23: 560-2. [CrossRef]

11. Cosmetic Surgery National Data Bank: Statistics, 2015. The American Society for Aesthetic Plastic Surgery website. http://www. surgery.org/media/statistics. Accessed April 1, 2016.

12. Khilnani AK, Thaddanee R. Clinical and demographic profile of cases requiring ear lobe repair in North Gujarat. Natl J Med Res 2013; 3:140-2.

13. Ribeiro AA, Lourenço L, Matsuda TMHB, Ferrari NM. Split earlobe repair: literature review and new technique proposal. Surg Cosmet Dermatol 2009; 1: 141-4.

14. Sharma R, Krishna S, Kumar S, Verma M. Rotation flap lobuloplasty: technique and experience with 24 partially torn earlobes. Int J Oral Maxillofac Surg 2014; 43: 1206-10. [CrossRef]

15. Boo- Chai K. The cleft ear lobe. Plast Reconstr Surg 1961; 28: 681-8. [CrossRef]

16. McLaren L. Cleft ear lobes: a hazard of wearing ear-rings. Br J Plast Surg 1954; 7: 162-5. [CrossRef]

17. Tan EC. Punch technique-an alternative approach to the repair of pierced earlobe deformities. J Dermatol Surg Oncol 1989; 15: 270-2. [CrossRef]

18. Abenavoli FM. Split earlobe: repair using a half Z-plasty technique. Plast Reconstr Surg 1996; 98: 372-3. [CrossRef] 
19. Miller TR, Eisbach KJ. Repair of enlarged pierced-ear openings. Ear Nose Throat J 2005; 84: 276-7.

20. Reiter D, Alford EL. Torn earlobe: a new approach to management with a review of 68 cases. Ann Otol Rhinol Laryngol 1994; 103: 879-84. [CrossRef]

21. Zoltie N. Split earlobes: a method of repair preserving the hole. Plast Reconstr Surg 1987; 80: 619-21. [CrossRef]
22. Rich JD, Gottlieb V, Shesol BF. A simple method for correction of the pixie earlobe. Plast Reconstr Surg 1982; 69: 136-8. [CrossRef]

23. de la Sotta P, Paredes N, Lasalle MA. Repair of dilated earlobe due to plug piercing. Dermatol Surg 2010; 36: 1621-3. [CrossRef]

24. Watson Effendi D. Repair of the torn earlobe. Facial Plast Surg 2004; 20: 39-45.[CrossRef] 